\title{
AÇÕES DE EDUCAÇÃO ALIMENTAR E NUTRICIONAL NA PROMOÇÃO DE PRÁTICAS ALIMENTARES SAUDÁVEIS EM IDOSAS DE UMA INSTITUIÇÃO DE LONGA PERMANÊNCIA
}

\author{
João Paulo Lima de Oliveira \\ Universidade Federal de Lavras \\ joaopaulolimanut@gmail.com \\ Monique Louise Cassimiro Inácio \\ Universidade Federal de Lavras \\ moniquelavras@hotmail.com \\ Débora Pereira Marcelino \\ Universidade Federal de Lavras \\ deborabio02@gmail.com
}

Isabela Naiara Freire Furtado Universidade Federal de Lavras isabela_macuco@hotmail.com

Luciana de Paiva Godinho Universidade Federal de Lavras luciana.godinho@gmail.com

Michel Cardoso De Angelis Pereira Universidade Federal de Lavras deangelis@ufla.br

\begin{abstract}
Resumo
A Educação Alimentar e Nutricional (EAN) é uma área do conhecimento considerada essencial para a promoção da saúde e prevenção de doenças. Contudo, existem poucos estudos desenvolvidos com idosos, população suscetível ao surgimento de enfermidades. O objetivo deste estudo foi desenvolver ações de EAN para a promoção da saúde por meio da melhoria das escolhas alimentares de idosas residentes em uma Instituição de Longa Permanência situada em Lavras, Minas Gerais, Brasil. Para tanto, foram conduzidas ações de EAN durante quatro meses, com 19 idosas, usando fundamentações metodológicas pautadas nos estudos de Paulo Freire e Johaan Henrich Pestalozzi, que advém para interpor caráter inovador na condução da EAN em detrimento das práticas tradicionais, como a educação bancária. Foram realizadas cinco ações com o intuito de construir o conhecimento acerca de alimentação e nutrição, estimulando a criticidade, autonomia e o empoderamento das idosas em suas escolhas alimentares. As intervenções realizadas apresentaram êxito quanto à melhoria das escolhas alimentares, demonstrando respostas positivas no uso de metodologias problematizadoras, desenvolvendo a autonomia quanto às escolhas alimentares saudáveis das idosas.
\end{abstract}

Palavras-chave: Saúde do Idoso. Prevenção de Doenças. Promoção da Saúde. Alimentação Saudável.

\section{FOOD AND NUTRITION EDUCATION ACTIONS TO PROMOTE HEALTHY FOOD PRACTICES IN ELDERLY PEOPLE FROM AN ASSISTED LIVING RESIDENCE}

\begin{abstract}
Abstrat
Food and Nutrition Education (FNE) is an area of knowledge considered essential for health promotion and disease prevention. However, there are few studies developed with the elderly, a population susceptible to the appearance of diseases. The aim of this study was to develop FNE actions for health promotion by improving the food choices of elderly residents of an Assisted Living Residence located in Lavras, Minas Gerais, Brazil. Thus, FNE actions were conducted for four months, with 19 elderly women, using methodological foundations based on the studies of Paulo Freire and Johaan Henrich Pestalozzi, which comes to interpose an innovative character in the conduct of FNE to the detriment of traditional practices, such as banking education. Five actions were carried out in order to build knowledge about food and nutrition, stimulating the criticality, autonomy and empowerment of elderly women in their food choices. The interventions performed were successful in improving food choices, showing positive responses in the use of problematizing methodologies, developing autonomy regarding the healthy food choices of the elderly.
\end{abstract}

Keywords: Health of the Elderly. Disease Prevention. Health Promotion. Diet Healthy. 
Ações de educação alimentar e nutricional na promoção de práticas alimentares saudáveis em idosas de uma instituição de longa permanência

\title{
ACCIONES DE EDUCACIÓN ALIMENTARIA Y NUTRICIONAL PARA PROMOVER PRÁCTICAS ALIMENTARIAS SALUDABLES EN PERSONAS MAYORES DE UNA INSTITUCIÓN DE LARGA ESTANCIA
}

\begin{abstract}
Resumen
La Educación Alimentaria y Nutricional (EAN) es un área de conocimiento considerada esencial para la promoción de la salud y la prevención de enfermedades. Sin embargo, existen pocos estudios desarrollados con ancianos, población susceptible a la aparición de enfermedades. El objetivo de este estudio fue desarrollar acciones de EAN para la promoción de la salud mediante la mejora de la elección de alimentos de los ancianos residentes de una Institución de Atención a Largo Plazo ubicada en Lavras, Minas Gerais, Brasil. Para ello, se realizaron acciones de EAN durante cuatro meses, con 19 mujeres mayores, utilizando fundamentos metodológicos basados en los estudios de Paulo Freire y Johaan Henrich Pestalozzi, lo que viene a interponer un carácter innovador en la conducción de EAN en detrimento de las prácticas tradicionales, como la educación bancaria. Se llevaron a cabo cinco acciones con el fin de generar conocimiento sobre alimentación y nutrición, estimulando la criticidad, autonomía y empoderamiento de las mujeres mayores en sus elecciones alimentarias. Las intervenciones realizadas tuvieron éxito en la mejora de la elección de alimentos, mostrando respuestas positivas en el uso de metodologías problematizadoras, desarrollando autonomía en la elección de alimentos saludables de los ancianos.
\end{abstract}

Palabras clave: Salud del Anciano. Prevención de Enfermedades. Promoción de la Salud. Dieta Saludable. 
Ações de educação alimentar e nutricional na promoção de práticas alimentares saudáveis em idosas de uma instituição de longa permanência

\section{INTRODUÇÃO}

Em países em desenvolvimento, como é o caso do Brasil, é considerado idoso, o sujeito cuja idade é igual ou superior a 60 anos (WHO, 2005). Com o aumento na expectativa de vida da população, houve crescimento na busca por Instituições de Longa Permanência para Idosos (IPLI) (IBGE, 2020). Essas, por sua vez, são caracterizadas como locais de acolhimento integral, onde idosos desprovidos da possibilidade de estarem com suas famílias são atendidos (ANVISA, 2005).

De acordo com a Pesquisa Nacional por Amostra de Domicílios (PNAD), desenvolvida através do Instituto Brasileiro de Geografia e Estatística (IBGE), no quarto trimestre de 2019 existiam 34 milhões de idosos no Brasil, o que equivale a 16,2\% da população total (IBGE, 2019). Em 2019, a expectativa de vida da população brasileira era de 76,6 anos, isto é, 31,1 anos a mais do que em 1940, quando foi iniciado o processo de envelhecimento da população (IBGE, 2019). Segundo dados do Instituto de Pesquisas Econômicas Aplicadas (IPEA), 83.870 idosos viviam em asilos sendo 5,5\% residentes de Instituições de Longa Permanência para Idosos (ILPI) públicas ou mistas (IPEA, 2010).

A Política Nacional de Saúde da Pessoa Idosa (PNSPI) salienta que esse grupo apresenta peculiaridades conforme sua história de vida, seu grau de independência funcional e a necessidade por serviços mais ou menos especializados. A avaliação do processo de envelhecimento deve ser pautada principalmente na realidade sociocultural na qual estão inseridos. Sendo assim, a PNSPI apresenta que se deve prezar pela recuperação, manutenção e favorecimento da autonomia e a independência desses sujeitos, estabelecendo estratégias coletivas e individuais de saúde para esse fim, em conformidade com os princípios e diretrizes do Sistema Único de Saúde (SUS) (BRASIL, 2006).

Vários profissionais devem compor a equipe multidisciplinar nas ILPIs, como médicos, enfermeiros, técnicos em enfermagem, psicólogo, fisioterapeuta, educador físico, cuidadores e nutricionista (ANVISA, 2005). O nutricionista possui presença obrigatória nesses locais, de acordo com a Resolução no 600, de 2018, do Conselho Federal de Nutrição (CFN, 2018). Este profissional é responsável por, dentre várias outras atribuições, realizar ações de Educação Alimentar e Nutricional (EAN), que visem à prevenção de doenças, promoção da saúde e boas práticas alimentares, o que são de relevante importância para a qualidade de vida deste público (CFN, 2018).

A EAN é caracterizada como um "campo do conhecimento de prática contínua, permanente, transdisciplinar, intersetorial e multiprofissional que visa promover a prática autônoma e voluntária de hábitos alimentares saudáveis" (BRASIL, 2012, p. 23). Possui como requisitos básicos o 
Ações de educação alimentar e nutricional na promoção de práticas alimentares saudáveis em idosas de uma instituição de longa permanência

desenvolvimento de abordagens educativas que permitam abranger os comportamentos alimentares em sua complexidade, tanto na dimensão biológica, como na social e cultural (ROCHA et al., 2016). Além disso, educar para a alimentação saudável exige a confrontação de novas práticas com as representações sociais dos alimentos e com o significado simbólico deles para os sujeitos do processo educativo. Isso caracteriza a ressignificação dos alimentos e a construção de novos sentidos para o ato de comer (BOOG, 2008).

Na década de 1980, houve uma transição no que tange às metodologias de ensino em EAN. O tecnicismo deu espaço à problematização, e a teoria proposta por Paulo Freire (1921-1997) apresentouse como base metodológica a ser seguida em intervenções dessa temática. Essa, por sua vez, parte do pressuposto de que a finalidade da educação é a formação de seres conscientes capazes de realizar transformações nas sociedades em que vivem. Nela, tanto o educador quanto o educando são transformados no processo de ensino-aprendizagem e ocorre o estímulo à consciência crítica da realidade (CHIARELLA, 2015), como demonstrado em estudo conduzido por Boog (2010), o qual utilizou essa base pedagógica em intervenções de EAN com famílias, professores e agricultores.

Com ideias pedagógicas similares, existe também o método intuitivo proposto por Johaan Henrich Pestalozzi (1746-1827). Pestalozzi foi um educador suíço que desenvolveu o método intuitivo para o ensino das diferentes disciplinas. Essa metodologia era baseada na tríade: sentidos (mãos), intelecto (cérebro) e sentimentos (coração), os quais trabalhavam de maneira conjunta de modo a construir conhecimento partindo do simples para o complexo e do concreto para o abstrato. Antes de construir o conhecimento, o educando era estimulado a perceber, sentir, ouvir, captar, olhar, apalpar, verificar, cheirar, tomar posse do objeto, tendo origem sempre da realidade mais próxima, para a mais distante. Assim, após todo esse processo de reconhecimento, o educando poderia finalmente formar os conceitos (OLIVEIRA, 2016). Estudos que utilizaram esta metodologia no ensino de EAN identificaram melhora no consumo alimentar, bem como no conhecimento sobre alimentação e nutrição (PEREIRA; INÁCIO; PEREIRA, 2020; INÁCIO, 2019).

Para o presente estudo, foram utilizadas as bases do método intuitivo proposto por Pestalozzi (1746-1827), e também da metodologia problematizadora de Paulo Freire (2011), haja vista a necessidade do desenvolvimento de ações em EAN, que abranjam o sujeito de forma holística considerando sua complexidade e o sistema alimentar, baseadas em metodologias atuais que busquem a formação de sujeitos autônomos, críticos e empoderados em suas escolhas alimentares (RAMOS; SANTOS; REIS, 2013).

Extensio: R. Eletr. de Extensão, ISSN 1807-0221 Florianópolis, v. 18, n. 39, p. 68-89, 2021. 
Ações de educação alimentar e nutricional na promoção de práticas alimentares saudáveis em idosas de uma instituição de longa permanência

Entendendo que ações de EAN podem garantir melhor qualidade de vida para o idoso, além de aumentar sua longevidade por meio da construção de melhores escolhas alimentares (CASAGRANDE et al., 2018), o objetivo do presente estudo foi desenvolver ações de EAN baseadas em metodologias Freirianas e Pestalozzianas para a promoção da saúde, buscando melhoria nas escolhas alimentares, com um grupo de idosas residentes em uma ILPI domiciliar de Lavras, Minas Gerais.

\section{MATERIAIS E MÉTODOS}

Este é um estudo com abordagem intervencionista, de ações em EAN com idosas em uma ILPI na cidade de Lavras-MG. Trata-se de uma instituição de pequeno porte que possui caráter domiciliar, uma vez que oferece casa individual para cada uma de suas residentes. Caracteriza-se como uma ILPI mista, pois recebe doações de outras instituições e as idosas também pagam um valor mensal para sua estadia. A escolha do local foi pautada pela demanda da própria instituição, que contactou os autores relatando a dificuldade de conscientização quanto ao consumo de alimentos entre as idosas. Os autores apresentaram a proposta do projeto para os administradores do local, obtendo a anuência para a execução das atividades. No local residiam 25 idosas e é dotado de horta e refeitório comunitário, além de espaço arborizado com quiosques, o que propicia às residentes o contato com a natureza.

Das 25 idosas, 19 atendiam aos critérios de inclusão, que eram a participante estar lúcida e orientada em tempo e espaço e ter interesse em participar das atividades. A instituição não dispõe de profissional nutricionista e por isso não houve participação desse profissional nas atividades. O projeto foi conduzido por graduandos do oitavo período do curso de Nutrição, que foram previamente treinados para a execução de cada atividade. O treinamento foi realizado durante cinco dias, duas semanas antes do início do estudo. Consistiu-se em reuniões com duas horas de duração, nas quais foi realizado o estudo profundo de cada metodologia a ser testada (método intuitivo e teoria problematizadora) e a padronização da condução das atividades.

No primeiro momento, foi identificada a capacidade mental e física das idosas por meio dos prontuários médicos cedidos pela equipe multidisciplinar aos autores, para verificação dos dados relacionados a cada uma delas. O presente estudo foi realizado durante quatro meses sequenciais (de outubro de 2016 a janeiro de 2017), seguindo um cronograma de encontros semanais, totalizando 
Ações de educação alimentar e nutricional na promoção de práticas alimentares saudáveis em idosas de uma instituição de longa permanência

oito visitas, sendo cinco delas destinadas à aplicação das intervenções com duração média de 1 hora e 30 minutos em cada uma delas.

As atividades realizadas foram pautadas na problematização, conforme proposto por Paulo Freire, concomitantemente com o método intuitivo, proposto por Johaan Henrich Pestalozzi. O arcabouço teórico de Paulo Freire salienta que tanto o educador quanto o educando são transformados no processo de ensino-aprendizagem, o qual busca o estímulo à consciência crítica da realidade (CHIARELLA et al., 2015). Já o método intuitivo é caracterizado pela constatação da essência antes das definições, onde o próprio aluno, intuitivamente, ou seja, após ter observado, analisado, comparado e trabalhado sobre determinada questão ou problema, descobre a solução por si mesmo (OLIVEIRA, 2016).

Foi realizada uma visita inicial para a análise do prontuário. Após isso, para a avaliação das demandas das idosas, foi realizada a roda de conversa em uma segunda visita. Foram conduzidas cinco intervenções, a saber: i) Palestra sobre alimentação saudável - produtos ultraprocessados x alimentos in natura; ii) Dinâmica "Laboratório dos Gostos"; iii) Valorização dos alimentos da Horta Comunitária do local; iv) Nutri Bingo e v) Reaproveitamento integral dos alimentos. Por fim, foi realizada a avaliação qualitativa das intervenções. Em todas as atividades houve a participação dos autores e das idosas. Apenas na quinta ação houve a participação da cozinheira da instituição.

\section{Roda de conversa com as idosas}

A atividade inicial consistiu da apresentação dos autores juntamente às idosas e, em seguida, foi instaurada uma roda de conversa baseada em assuntos sobre alimentação. Esta, por sua vez, também foi utilizada para avaliação do conhecimento e detecção das demandas das idosas em relação às intervenções. Os prontuários analisados, a priori, para o conhecimento das patologias e demais informações advindas da anamnese, foram os precursores para formulação das questões a serem investigadas, como, por exemplo: o excesso do consumo de açúcar, gorduras e sódio são prejudiciais à saúde? Esses nutrientes podem estar relacionados ao desenvolvimento de doenças? Quais alimentos devem ser ingeridos com cautela por portadores de doenças crônicas não transmissíveis (DCNT's)? Qual a importância de se consumir uma alimentação com variedade, equilíbrio e harmonia? Desta forma, a partir das respostas e indagações identificadas na roda de conversa, foi possível elaborar ações

Extensio: R. Eletr. de Extensão, ISSN 1807-0221 Florianópolis, v. 18, n. 39, p. 68-89, 2021. 
Ações de educação alimentar e nutricional na promoção de práticas alimentares saudáveis em idosas de uma instituição de longa permanência

de EAN focadas, caracterizando uma das atividades do projeto, onde foi feito o primeiro contato com as idosas e investigado suas expectativas sobre as intervenções que viriam a seguir.

\section{Palestra sobre alimentação saudável: produtos ultraprocessados $\mathrm{x}$ alimentos in natura}

Esta atividade buscou expor os desfechos adversos à saúde relacionados ao consumo excessivo de produtos ultraprocessados. As patologias diabetes e doenças cardiovasculares foram o tema central para a interação. Ademais, foi discutida a importância do consumo de alimentos in natura e minimamente processados para a manutenção de bons hábitos alimentares utilizando a dialogicidade como proposto por Paulo Freire (2011). Nessa pedagogia, ambos educadores e educandos constroem o conhecimento de maneira integrada, sem que haja mera transferência do conteúdo, excluindo qualquer atitude que possa caracterizar um sistema de educação bancária.

Com embasamento teórico pautado no Guia Alimentar para a População Brasileira (BRASIL, 2014), a palestra de caráter dialógico teve início com a discussão acerca dos tipos de alimentos de acordo com a nova classificação proposta pelo documento supracitado. Como exemplo de alimentos in natura, foram utilizadas imagens de frutas, legumes e hortaliças. Para produtos ultraprocessados, foram utilizados o macarrão instantâneo, refrigerante, biscoito recheado e suco industrializado. Com o decorrer da atividade foi construído conhecimento acerca dos desfechos adversos de uma alimentação rica em produtos com alto processamento. Para enriquecer a discussão, imagens foram utilizadas representando as consequências das diversas patologias relacionadas à má alimentação, como o "pé diabético", glaucoma e problemas de cicatrização.

Todas as idosas foram estimuladas a explanarem sobre suas experiências e, em conjunto aos autores, construir o conhecimento em torno da temática, tornando o processo de problematização mais efetivo.

\section{Dinâmica "Laboratório dos Gostos"}

O método intuitivo proposto por Pestalozzi preconiza que as capacidades intelectuais (cérebro), morais (coração) e físicas (mãos), deveriam se desenvolver simultaneamente, fomentadas pela atividade prática e sociável (OLIVEIRA, 2016). Considerando esse cenário, esta atividade buscou,

por meio dos sentidos (olfato, paladar, tato e visão), identificar as recordações das idosas em torno dos

Extensio: R. Eletr. de Extensão, ISSN 1807-0221 Florianópolis, v. 18, n. 39, p. 68-89, 2021. 
Ações de educação alimentar e nutricional na promoção de práticas alimentares saudáveis em idosas de uma instituição de longa permanência

alimentos. Para tanto, a dinâmica "Laboratório dos gostos", proposta no estudo, é baseada no "Instrutivo: Metodologia de trabalho em grupos para ações de alimentação e nutrição na atenção básica”, proposto pelo Ministério da Saúde (BRASIL, 2016).

Para a realização desta dinâmica, as idosas foram vendadas, sendo oferecido uma porção de queijo para degustação. Em seguida, elas indicaram qual alimento tinha sido ingerido. No que diz respeito ao tato, as idosas retiraram de uma caixa um alimento (tomate), e tiveram também que utilizar de suas intuições e experiências para descobrir de qual gênero alimentício se tratava.

Para estímulo do olfato foram utilizados como matéria-prima a cebolinha e salsinha, que são alimentos característicos devido a seu odor. Em relação à visão, foi utilizado um alimento não muito comum no cotidiano das idosas, o qual seria fácil de ser confundido com outros. Para tanto, foi escolhido o espinafre.

Após a revelação de todos os alimentos escolhidos para esta dinâmica, foi construído o conhecimento acerca da importância alimentar e nutricional de cada um.

\section{Valorização dos alimentos da Horta Comunitária do local}

Dois dos postulados de Pestalozzi citam a valorização da natureza para a composição do conhecimento e também o resgate das lembranças por meio dos sentimentos (OLIVEIRA, 2016). Nessa perspectiva, as idosas foram convidadas a ir até a horta comunitária e, naquele ambiente, foram orientadas a caminhar e explorar, de modo que apontassem os alimentos de sua preferência para o cultivo, bem como suas motivações para escolha desses gêneros. Isso propiciou o resgate das lembranças, e também o contato com o ambiente.

Neste momento, foi discutida a proposta inicial desta atividade, que era a reflexão da representatividade daqueles alimentos para as idosas, tendo como argumento as lembranças que eles traziam para cada uma delas. Essa representatividade dos alimentos tem como propósito o resgate da vida pregressa e as socializações ocorridas por meio deles. Para tanto, foi proposto que as idosas realizassem o cultivo dos gêneros alimentícios que traziam as lembranças para o resgate dos prazeres sociais promovidos pela alimentação.

Além de incentivar o consumo de alimentos saudáveis e o cultivo dos mais preferidos, essa intervenção também trabalhou o resgate da cultura das mesmas, buscando conhecer, partilhar a história de vida e costumes de cada uma, ressaltando, principalmente, a importância dos alimentos naturais que 
Ações de educação alimentar e nutricional na promoção de práticas alimentares saudáveis em idosas de uma instituição de longa permanência

estavam sendo cultivados, bem como os nutrientes que cada um deles contém, o que caracteriza a metodologia de Pestalozzi.

\section{"Nutri Bingo"}

Essa atividade teve como objetivo estimular as idosas a construírem conhecimento de maneira dialógica acerca das propriedades nutricionais de alguns alimentos. Para a adaptação às dificuldades visuais, foram elaboradas cartelas ampliadas e coloridas buscando melhor compreensão das idosas. A escolha desses alimentos considerou a sazonalidade do momento em que essa intervenção foi desenvolvida (Dezembro/2019). Foram incluídos abacaxi, banana prata, damasco, ameixa, limão, pêssego, lichia, figo, maçã, manga, maracujá, melancia, melão, uva, abobrinha, beterraba, cenoura, pimentão, tomate, vagem, almeirão, cebolinha, hortelã, rúcula e salsa.

Como em uma sessão de bingo tradicional, as cartelas do "Nutri Bingo" e os marcadores foram distribuídos. A cada alimento sorteado, era instaurada uma roda de conversa sobre os nutrientes e suas funções no organismo, levando à construção do conhecimento de maneira conjunta, de modo a valorizar a cultura das idosas, contrariando a educação bancária que é caracterizada pela transferência do conhecimento do educador para o educando sem considerar suas falas e experiências, o que Paulo Freire (2011) desmotivava. Após a roda de conversa, outro alimento era sorteado, e uma nova roda de conversa era instaurada. Isso foi feito até que se falasse de todos os alimentos propostos. Ao final do jogo, todas as idosas receberam uma muda a ser plantada na horta comunitária como presente.

\section{Reaproveitamento integral dos alimentos}

Com base na tríade do conhecimento apresentada por Pestalozzi (sentimentos, intelecto e sentidos), os sentidos foram estimulados por meio do sabor, odor, tato e visão, levando às lembranças e experiências vividas (OLIVEIRA, 2016). Nessa perspectiva, foi elaborado um bolo de casca de abóbora com o intuito de construir conhecimento em torno da redução do desperdício e aproveitamento integral dos alimentos, além da valorização da culinária por meio dos sentidos, e consequentemente, o resgate das experiências das idosas.

A preparação da receita foi realizada no refeitório do local, onde as idosas foram alocadas ao redor da mesa e ficaram observando, enquanto os autores, juntamente com a cozinheira, foram 
Ações de educação alimentar e nutricional na promoção de práticas alimentares saudáveis em idosas de uma instituição de longa permanência

realizando os procedimentos para elaboração da receita; posteriormente, um café dialogado foi proposto para se degustar o bolo e discutir em torno da temática da atividade, o que contou com a participação da cozinheira da instituição. Primeiramente, foram questionados qual o sabor da preparação e quais os ingredientes utilizados para sua elaboração. No decorrer dos diálogos, foram discutidos os insumos presentes na receita, estimulando a valorização do alimento em sua integralidade. As recordações das idosas relacionadas aos gêneros alimentícios inerentes à preparação foram expostas espontaneamente, conforme os propósitos do próprio método adaptado para EAN, possibilitando melhor assimilação dos conteúdos abordados.

\section{Avaliação qualitativa das intervenções realizadas com as idosas}

A avaliação das intervenções foi realizada por meio de entrevista semiestruturada, realizada individualmente após o final do projeto. Teve o objetivo de identificar a efetividade das ações, conforme a coleta de informações sobre o aprendizado em alimentação e nutrição adquiridos pelas idosas. Além disso, por meio da entrevista, foi possível constatar as atividades preferidas, experiências vivenciadas e mudanças das práticas alimentares. Todas as falas foram gravadas e transcritas para posterior análise.

\section{RESULTADOS}

\section{Roda de conversa com as idosas}

Baseado nos conhecimentos pessoais, cada idosa expôs sua relação com a alimentação associando com a condição patológica existente, principalmente com os mitos impostos pela população acerca da alimentação. Foram solicitados exemplos práticos de maneiras para melhorar a qualidade da alimentação a ser ingerida, considerando as características socioeconômicas. Partindo desse pressuposto, ficou evidente que as idosas demonstraram responsividade à metodologia adotada, uma vez que apresentaram exemplos que demonstraram o aprendizado.

Os autores também aproveitaram o momento de apresentação para provocar mais questionamentos sobre a alimentação de cada idosa. Consequentemente a isso, foi observada crescente interação e empatia entre os autores e as idosas, e, também, foi identificada a relação inversamente

Extensio: R. Eletr. de Extensão, ISSN 1807-0221 Florianópolis, v. 18, n. 39, p. 68-89, 2021. 
Ações de educação alimentar e nutricional na promoção de práticas alimentares saudáveis em idosas de uma instituição de longa permanência

proporcional de consumo de produtos industrializados para alimentos in natura observando, portanto, elevada ingestão do primeiro e baixa do segundo, respectivamente. A análise do prontuário feita a priori teve o objetivo de constatar as doenças presentes entre as idosas e, assim, planejar, elaborar e executar ações focadas e eficientes considerando suas necessidades. Não foi calculado o percentual das doenças mais recorrentes, pois o intuito foi identificar quais comorbidades estavam presentes para que as ações de EAN fossem realizadas baseadas nisso, independentemente da quantidade de casos.

\section{Palestra sobre alimentação saudável: alimentos industrializados $\mathrm{x}$ alimentos in natura}

A palestra foi provocativa, conduzindo os questionamentos e participações das idosas na proporção que o diálogo se estabelecia, formando a construção participativa dos conceitos. Quando levantadas questões sobre o consumo de produtos industrializados, foi relatado alto consumo de alimentos contendo açúcares, gorduras e sódio, visto que esses produtos possuem elevadas quantidades desses ingredientes e, consequentemente, podem acarretar malefícios à saúde quando consumidos em excesso, sendo esses alimentos classificados como ultraprocessados. Conforme o que foi relatado pelas idosas sobre o consumo de grandes quantidades de alimentos ultraprocessados, foi dialogado e trabalhado pelos autores que, tais nutrientes presentes nesses alimentos (açúcares, gorduras e sódio), podem ser altamente prejudiciais ao organismo quando consumidos em excesso, sendo utilizadas analogias para facilitar o entendimento das idosas para as patologias retratadas na palestra.

O momento mais importante dessa atividade foi o diálogo construído sobre as patologias associadas à alimentação. A atividade causou curiosidade, enriquecendo assim o processo de problematização e tornando as idosas mais reflexivas. Por meio dessa atividade, as idosas puderam construir conceitos acerca dos requisitos para se ter uma alimentação adequada e saudável e, assim, prevenir doenças como as demonstradas na atividade.

\section{Dinâmica "Laboratório dos Gostos"}

Após todas as idosas serem vendadas, os alimentos foram apresentados e cada órgão do sentido foi estimulado. O tomate foi reconhecido por quinze idosas no primeiro toque das mãos. As demais levaram alguns minutos a mais para reconhecê-lo. Por meio deste alimento, foram relatadas histórias

Extensio: R. Eletr. de Extensão, ISSN 1807-0221 Florianópolis, v. 18, n. 39, p. 68-89, 2021. 
Ações de educação alimentar e nutricional na promoção de práticas alimentares saudáveis em idosas de uma instituição de longa permanência

relacionadas ao plantio e modo de preparo pelas idosas. E os autores inseriram a discussão acerca das substâncias funcionais do tomate, como o licopeno.

No que diz respeito ao olfato, a cebola e a salsa foram usadas como matéria pedagógica. Todas as idosas reconheceram esses alimentos no primeiro cheiro. Elas relataram utilizar no preparo de suas refeições. Isso aconteceu também, quando foi estimulado o paladar usando o queijo, visto que, a totalidade das idosas o reconheceu no primeiro contato. Os autores problematizaram junto a elas a respeito do processo de produção do queijo e a importância do cálcio, muito presente nesse alimento.

O espinafre foi a matéria pedagógica escolhida para estímulo do último sentido, a visão. No primeiro contato visual, o alimento foi reconhecido por todas as idosas e a aprendizagem se deu no que cerne a riqueza de vitaminas e minerais presentes neste alimento, exemplificadas pelas vitaminas do complexo B e o cálcio.

\section{Valorização dos alimentos da Horta Comunitária do local}

$\mathrm{Na}$ horta comunitária da instituição, as atividades foram iniciadas abordando a valorização dos alimentos num processo de interação entre os profissionais de saúde e as idosas, buscando a valorização dos alimentos já cultivados.

Foram adquiridas, em um mercado local, mudas de vegetais e legumes para incremento da horta. Concomitante a isso, o processo educativo foi continuado, aproveitando a prática do plantio para aprimoramento do conhecimento sobre sustentabilidade e funções dos nutrientes como proteína, cálcio, zinco, vitaminas do complexo B e vitaminas lipossolúveis, promovendo maior ênfase nessas últimas por atuarem como antioxidantes.

Entendendo a importância para a manutenção da saúde psicológica e física, as idosas foram estimuladas a participarem da conservação da horta, situação que levou à maior consciência e assimilação dos conhecimentos adquiridos. Adicionado a isso, com a valorização dos alimentos produzidos no local, houve diminuição dos gastos com hortaliças, podendo este valor ser empregado em outros alimentos que agregam bom aporte nutricional às idosas.

A intervenção resgatou memórias afetivas acerca de alimentos consumidos na juventude das educandas e que poderiam ser cultivados no local. As idosas receberam a proposta com ânimo. As que dispunham de condições físicas imediatamente se manifestaram para realizar a revitalização da horta e cultivar as mudas que lhe foram ofertadas. O diretor da instituição se propôs a comprar outras espécies

Extensio: R. Eletr. de Extensão, ISSN 1807-0221 Florianópolis, v. 18, n. 39, p. 68-89, 2021. 
Ações de educação alimentar e nutricional na promoção de práticas alimentares saudáveis em idosas de uma instituição de longa permanência

de plantas de acordo com o pedido das idosas. A proposta de cultivar seu próprio alimento foi relatada por elas como uma forma de aumentar a qualidade nutricional da alimentação na instituição, promover saúde e prevenirem-se contra os agravos à saúde.

\section{"Nutri Bingo"}

Nessa atividade buscamos valorizar a sazonalidade por meio do estímulo ao consumo de alimentos in natura amadurecidos na época. Concomitante ao sorteio do alimento, foi discutida a importância do consumo desses gêneros alimentícios para a manutenção do bom funcionamento do organismo e as idosas explanaram suas lembranças sobre eles.

Durante a realização do Nutri Bingo, algumas das idosas relataram não conhecer certas frutas ou vegetais, e este fato foi determinante para que elas refletissem sobre o ato de comer como algo fácil e que existem vários meios para consegui-los. Ao final, foram distribuídas mudas de vegetais a serem plantados na horta comunitária do local. Por meio desta ação, foi despertado o interesse pelo cultivo do seu próprio alimento, além do estímulo ao desenvolvimento de habilidades culinárias, o que desqualifica o consumo de alimentos prontos.

\section{Reaproveitamento integral dos alimentos}

O relato das idosas demonstrou que a aceitabilidade foi satisfatória em relação ao alimento, sobre o qual informou-se que a textura, a aparência, o sabor e o odor não influenciaram no aspecto geral, partindo do pressuposto de que o principal ingrediente da preparação foi a casca da abóbora. A pergunta norteadora foi discutida e os autores, em conjunto com as idosas, abordaram a importância do consumo de cascas e talos, pois também são partes dos alimentos que possuem nutrientes e, muitas vezes, são desprezados.

A partir disso, foi observada a necessidade da implementação de um livro de receitas, onde os principais ingredientes seriam partes de alimentos não utilizados em suas rotinas. A cozinheira apontou a viabilidade desse material, tendo como justificativa a grande demanda por elaboração de quitandas, semanalmente, o que poderia amenizar os custos e aumentar a variedade e disponibilidade das preparações. 
Ações de educação alimentar e nutricional na promoção de práticas alimentares saudáveis em idosas de uma instituição de longa permanência

\section{Avaliação qualitativa das intervenções realizadas com as idosas}

Para a avaliação qualitativa, foi cedido um espaço na rotina das idosas, pelos coordenadores do local, somente no período matutino e com tempo cronometrado, pois as idosas também tinham aula de ginástica logo após as visitas, sendo assim, durante o planejamento das atividades, foi levado em consideração que a avaliação qualitativa seria realizada no final do projeto de extensão.

Antes de iniciar a aplicação das entrevistas individuais, foi realizada uma revisão dos nomes das intervenções conduzidas, visando driblar o problema de memória inerente nessa população. Fato este que foi efetivo, pois, fez com que as idosas se lembrassem das intervenções conduzidas e também das mudanças ocorridas após o seu término.

Dentre os assuntos discutidos, percebemos que o consumo exagerado de sal e açúcar teve maior impacto para as idosas. Uma das idosas relatou: "aprendi que o sal é prejudicial à saúde, pois, sobe a pressão, e comer muito açúcar dá diabetes". E, ainda, outra idosa completou: "a diminnição do sal e açúcar ajuda a prevenir doenças". Outra participante relatou: "en gosto de comer miojo à noite, mas agora en sei que ele possui muito sal e óleo, e então não uso o tempero que vem no miojo". Uma terceira idosa disse: "miojo é muito gorduroso e far mal”.

Outra moradora resgatou lembranças da primeira palestra: "lembro daquela mulher gordona na cama que não conseguia fechar a perna, porque ela comeu muito açúcar e teve diabetes". E ainda lembrou do brinde que foi dado na intervenção "Nutri Bingo": "ganhamos uma mudinha pra cuidar na horta e lembro do queijo que experimentei que tem cálcio, do tomate que eu levei pra casa e que tem vitamina. Teve também a cebolinha e a salsinha que serve de tempero no lugar do sal. Lembro também que você falou muito da acerola que tem aqui atrás da cožinha".

Uma das residentes da instituição disse: "o leite tem cálcio que é bom para os ossos" e uma outra complementou "o leite é bom porque tem cálcio e vai fortalecer nossos ossos". A respeito das frutas, mesmo sendo um grupo de alimentos que não é consumido periodicamente, a idosa mais popular entre as residentes (93 anos), falou: "gosto de comer muita fruta porque é macia". E ainda em relação às frutas, outra moradora disse: "as frutas devem ser consumidas porque são ricas em vitaminas".

Apesar das limitações dessa avaliação qualitativa, foi possível observar que as ações realizadas com as idosas foram efetivas, isto é, as idosas conseguiram reproduzir o que foi aprendido durante as ações em suas vidas, pois houve a mudança de escolhas alimentares.

Extensio: R. Eletr. de Extensão, ISSN 1807-0221 Florianópolis, v. 18, n. 39, p. 68-89, 2021. 
Ações de educação alimentar e nutricional na promoção de práticas alimentares saudáveis em idosas de uma instituição de longa permanência

\section{DISCUSSÃO}

Por meio da roda de conversa inicial, foi identificado que o consumo alimentar relatado pelas idosas é majoritariamente composto por produtos industrializados e, minimamente, por alimentos naturais. Ademais, as comorbidades mais recorrentes entre elas são o diabetes tipo II, hipertensão, obesidade e hipercolesterolemia. Estudos apontam a associação entre o elevado consumo de produtos ultraprocessados e DCNT como o diabetes, a obesidade e as dislipidemias, não somente em outras faixas etárias como crianças e adultos, mas também em idosos (MELO; MELLO; COELHO, 2020; ANDRETTA et al., 2019; MONTEIRO et al., 2011; WHO, 2003).

Esses desfechos observados na população em questão, estão relacionados com o alto consumo de alimentos ultraprocessados que irão impactar no desenvolvimento ou na progressão de doenças, como demonstrado no estudo de Melo, Mello e Coelho (2020), no qual foi identificada a ingestão excessiva de produtos alimentícios altamente processados em idosas, associada à hipertensão, corroborando com o presente estudo. Considerando esse contexto, Cervato et al. (2005) relatam a importância do desenvolvimento de ações em EAN na redução ou até mesmo na solução de problemas de saúde advindos de práticas alimentares inadequadas.

No que se refere à atuação do nutricionista em ILPI's, segundo a resolução do CFN n 600 , prevê a atuação de nutricionista nesse âmbito, atuando para realizar triagem de risco nutricional quando da admissão do idoso, elaborar o diagnóstico de nutrição, elaborar a prescrição dietética, com base nas diretrizes do diagnóstico de nutrição e, considerando as interações drogas/nutrientes e nutrientes/nutrientes, registrar em prontuário do idoso a prescrição dietética e a evolução nutricional, de acordo com protocolos pré-estabelecidos pela Unidade de Nutrição e Dietética (UND), entre outras atividades. Entretanto, há uma carência de estudos na literatura relatando a atuação de nutricionistas nessas instituições. Contudo, Mendes e Oliveira (2018) reportam que, dependendo do porte de uma ILPI, um nutricionista atuando por 30 horas semanais é inviável, pois, a implementação de estratégias de intervenção nutricional deve ser planejada com acurácia, visando à garantia da qualidade de vida dos idosos residentes de uma ILPI. Logo, uma carga horária mínima (30 horas) não garante a qualidade no serviço a ser prestado (MENDES; OLIVEIRA, 2018). Ademais, segundo a Resolução RDC nº 283 (ANVISA, 2005), que regulamenta as normas de funcionamento para as ILPI's, descreve que, para o serviço de alimentação, recomenda-se um profissional para cada 20 idosos, garantindo a cobertura de dois turnos de 8 horas. Diante do exposto, conforme as atribuições do nutricionista para atuar numa

Extensio: R. Eletr. de Extensão, ISSN 1807-0221 Florianópolis, v. 18, n. 39, p. 68-89, 2021. 
Ações de educação alimentar e nutricional na promoção de práticas alimentares saudáveis em idosas de uma instituição de longa permanência

ILPI, é sugerido que a resolução no 283 seja reformulada, pois essa carga horária mínima de trabalho inviabiliza a atuação do nutricionista de forma a atender todas as demandas previstas no seu respectivo conselho de classe.

No presente estudo, desenvolvemos intervenções provocativas e dialógicas que estimulavam a criticidade, autonomia, empoderamento e que valorizavam as experiências das educandas. Para tanto, essas ações foram baseadas na metodologia problematizadora de Paulo Freire (2011). Essa, por sua vez, explicita que o conhecimento está sempre em construção e, portanto, ele nunca está pronto e acabado. Nessa pedagogia, inicialmente, o aluno conta sobre suas experiências e a aprendizagem se desenvolve por meio daquilo que é conhecido por ele. Após isso, existe a problematização que, por meio de uma visão crítica do mundo, realiza transformações no contexto vivido (BECK, 2016).

Outros autores (BOOG, 2010; GRILO et al., 2016) têm utilizado a pedagogia dialógica supracitada em suas pesquisas em EAN. Assim como no presente estudo, foram identificados resultados satisfatórios na mudança de escolhas alimentares e também no empoderamento e valorização da história dos educandos. Em estudo conduzido por Boog (2010), foi identificado que a pedagogia dialógica empregada estimulou o interesse pelas atividades, uma vez que estas refletiam o cotidiano e valorizavam o trabalho, a história e a cultura, fortalecendo a autoestima dos participantes. $\mathrm{Na}$ população idosa não são encontrados estudos que utilizaram essa metodologia, o que reafirma o caráter inovador no presente estudo.

Com o decorrer das intervenções, foi observada a criação de um laço afetivo entre os autores e as idosas. O dado cenário é de grande importância no processo de ensino-aprendizagem, haja vista que, segundo Pestalozzi, é o amor que desencadeia igualmente o processo de aprendizagem, pois ao sentir a confiança que o educador deposita em todas as suas potencialidades e estimulado por essa confiança, o educando se vê também seguro para se apoderar autonomamente do processo de conhecimento (INCONTRI, 1997).

Conduzido em meio à natureza e valorizando os conhecimentos de seus educandos, o método intuitivo preconiza o ensino partindo do que se é conhecido e concreto, para o desconhecido e abstrato, de modo que os sentimentos, sentidos e intelecto trabalhem em harmonia no processo de aprendizagem, ou seja, Pestalozzi preconizava a integração entre a racionalidade, sentimento e a prática, de maneira que não se valorizasse somente o raciocínio, mas também o desenvolvimento da moral e do sujeito enquanto ser social (ALVES, 2014; INCONTRI, 1997).

Extensio: R. Eletr. de Extensão, ISSN 1807-0221 Florianópolis, v. 18, n. 39, p. 68-89, 2021. 
Ações de educação alimentar e nutricional na promoção de práticas alimentares saudáveis em idosas de uma instituição de longa permanência

Todas as intervenções desenvolvidas neste estudo foram realizadas próximas da natureza e em conjunto, propiciando o toque, a observação, a análise e, consequentemente, o acesso a emoções e lembranças, como identificado nos postulados do método intuitivo. Por meio do emprego dessa base teórico-pedagógica, houve melhora nas práticas alimentares e no conhecimento sobre alimentação e nutrição por parte das idosas. E isso se deve ao fato de se colocar o educando enquanto centro da sua história, valorizando sua experiência, cultura e estimulando seu empoderamento e autonomia, como encontrado em estudo de Inácio (2019), de maneira que, pelo uso do método intuitivo e valorização dos aspectos supracitados, foi atingido o aumento no conhecimento sobre alimentação e nutrição, diminuição no consumo de produtos ultraprocessados e aumento nos alimentos minimamente processados.

A partir deste estudo, as idosas, munidas de conhecimento, tiveram sua criticidade desenvolvida, passando da ingênua para a epistemológica e, assim, passaram a ter autonomia e maior empoderamento em suas escolhas alimentares saudáveis (FREIRE, 2011). Partindo do pressuposto de que idosos que moram sozinhos possuem piores hábitos alimentares e condição de saúde, entendese que realizar suas próprias aquisições alimentares é uma tarefa difícil (KAWAKAMI et al., 2020), contudo, no presente estudo, foi identificado que, após as intervenções, as idosas passaram a conhecer os efeitos do excesso do consumo de determinados alimentos no corpo, e assim optar por gêneros alimentícios benéficos para sua saúde. Ou seja, tiveram sua criticidade, autonomia e empoderamento desenvolvidos.

Empoderamento pode ser definido como o resultado de um processo de conhecimento que resulta no domínio sobre a sua própria vida e na capacidade de tomar decisões sobre o que lhe diz respeito ( DICIO, 2020; PERONDI, 2020). Nessa perspectiva, a EAN é uma estratégia de promoção da autonomia e empoderamento do sujeito, no que tange às escolhas alimentares e ao autocuidado, pois atua de maneira holística estimulando a aprendizagem sobre a alimentação e nutrição da população.

Entendendo que a EAN é um campo do conhecimento de transdisciplinaridade que busca promover o desenvolvimento autônomo e voluntário de práticas alimentares saudáveis, sua importância na promoção da saúde e prevenção de doenças perpassa não somente por crianças e adultos, mas também em idosos. Em estudo, conduzido por Wallace e Devine (2016), foi identificando aumento no consumo de alimentos naturais, assim como no conhecimento de idosos após a aplicação de ações de EAN por quatro semanas. Nessa mesma linha, Chung e Chung (2014) identificaram 
Ações de educação alimentar e nutricional na promoção de práticas alimentares saudáveis em idosas de uma instituição de longa permanência

melhora no apetite e das habilidades culinárias de idosos submetidos a intervenções de EAN. Isso se deve à valorização do sujeito, de sua cultura, bem como suas experiências e demandas para a elaboração das atividades de alimentação e nutrição. A EAN, enquanto meio de estímulo ao empoderamento, criticidade e autonomia do educando, propiciando a construção do conhecimento de maneira sólida e eficiente, resulta em melhores escolhas alimentares e qualidade de vida (BARBOSA et al., 2013), como demonstrado no presente estudo.

As refeições da ILPI, onde as idosas residiam, eram, em sua maioria, baseadas em alimentos in natura e minimamente processados, e o cardápio era montado pelas cozinheiras, já que não havia nutricionista no local. As idosas tinham a opção de comer no local ou não. Em estudo conduzido por Camargos e colaboradores (2015), foi constatado que em 81\% das ILPIs privadas de Minas Gerais há a presença de nutricionistas, o que não corrobora com o presente estudo.

Além disso, na ILPI da pesquisa, as idosas tinham a opção de ir até o supermercado e comprar seus próprios alimentos, além das refeições servidas. Antes das intervenções, as idosas relataram comprar grandes quantidades de alimentos ultraprocessados, como sucos industrializados, biscoitos recheados e macarrão instantâneo. Após as ações, elas relataram ingerir a comida da ILPI e passaram a comprar gêneros alimentícios saudáveis, como frutas.

Como possível limitação do estudo, podemos indicar a duração das ações, haja vista que, Murimi et al. (2017) apontam que, para que as atividades de EAN sejam efetivas, elas devem ser desenvolvidas em um período igual ou superior a cinco meses. Nessa mesma linha, o Marco de Referência em Educação Alimentar e Nutricional para as Políticas Públicas (BRASIL, 2012) destaca a necessidade de se ter ações de EAN de maneira contínua e permanente, o que não ocorreu no presente estudo. Contudo, mesmo não tendo a duração recomendada, foram encontrados resultados satisfatórios, no que tange à escolha alimentar saudável.

Trata-se de um estudo inovador na área, pois não são encontrados na literatura trabalhos conduzidos com essa população, utilizando as metodologias de Paulo Freire e Johaan Henrich Pestalozzi na área de EAN. Apenas um estudo foi conduzido com crianças e adolescentes com o uso dessas bases pedagógicas (INÁCIO, 2019). Fato este que destaca o caráter inovador do presente estudo na saúde coletiva e convida os pesquisadores a desenvolverem novas pesquisas abrangendo essa temática com a dada população. Para a extensão em EAN, esse trabalho apresenta uma nova alternativa de planejamento, elaboração e execução de ações nessa área do conhecimento com este público-alvo.

Extensio: R. Eletr. de Extensão, ISSN 1807-0221 Florianópolis, v. 18, n. 39, p. 68-89, 2021. 
Ações de educação alimentar e nutricional na promoção de práticas alimentares saudáveis em idosas de uma instituição de longa permanência

\section{CONSIDERAÇÕES FINAIS}

A abordagem metodológica proposta demonstrou boa aceitação e efetividade, haja vista a melhora nas escolhas alimentares e no conhecimento sobre alimentação e nutrição por parte dos relatos das idosas. As ações realizadas para a promoção da EAN auxiliaram e contribuíram para que as idosas desenvolvessem a sua própria autonomia. As idosas se envolveram no processo de ensinoaprendizagem, desenvolvendo ao longo das atividades maior curiosidade epistemológica, estabelecendo, portanto, pensamento mais crítico e mudança no comportamento quanto às escolhas alimentares.

\section{REFERÊNCIAS BIBLIOGRÁFICAS}

AGÊNCIA NACIONAL DE VIGILÂNCIA SANITÁRIA - ANVISA. Resolução da diretoria colegiada- $\mathrm{RDC}^{\circ}$ 283, de 26 de Setembro de 2005. Aprova o Regulamento Técnico que define normas de funcionamento para as Instituições de Longa Permanência para Idosos. Diário Oficial da União; Poder Executivo, de 27 de setembro de 2005. Disponível em:https://sbgg.org.br/wp-content/uploads/2014/10/rdc-283-2005.pdf Acessado em: 10 abr. 2021.

ALVES, W. O. Pestalozzi: Um romance pedagógico. Rio de Janeiro: Editora Ide, 2014. 304 p.

ANDRETTA, V; SIVIERO, J.; MENDES, G. K.; MOTTER, F. R.; THEODORO, H. Consumo de alimentos ultraprocessados e fatores associados em uma amostra de base escolar pública no sul do Brasil. Ciência e Saúde Coletiva, 2019. Disponível em http://www.cienciaesaudecoletiva.com.br/artigos/consumo-de-alimentos-ultraprocessados-efatores-associados-em-uma-amostra-de-base-escolar-publica-no-sul-do-brasil/17271 ?id=17271. Acesso em: 28 junho 2020.

BARBOSA, N. V. S. et al. Alimentação na escola e autonomia - desafios e possibilidades. Ciência e Saúde Coletiva, v. 18, n. 4, p. 937-945, 2013.

BECK, C. Método Paulo Freire de alfabetização. Andragogia Brasil, 2016. Disponível em: https://andragogiabrasil.com.br/metodo-paulo-freire-de-alfabetizacao/. Acesso em: 28 junho 2020.

BOOG, M. C. F. Atuação do nutricionista em saúde pública na promoção da alimentação saudável. Revista Ciência e Saúde, Porto Alegre, v.1, n.1, p. 33-42, 2008.

BOOG, M. C. F. Programa de educação nutricional em escola de ensino fundamental de zona rural. Revista de Nutrição, v. 23, n.6, Campinas, v. 23, n.6, p. 1005-1017, 2010. 
Ações de educação alimentar e nutricional na promoção de práticas alimentares saudáveis em idosas de uma instituição de longa permanência

BRASIL. Ministério da Saúde. Universidade Federal de Minas Gerais. Instrutivo: metodologia de trabalho em grupos para ações de alimentação e nutrição na atenção básica. Brasília: Ministério da Saúde, 2016. 168 p.

BRASIL. Ministério do Desenvolvimento Social e Combate à Fome. Secretaria Nacional de Segurança Alimentar e Nutricional. Marco de referência de educação alimentar e nutricional para as políticas públicas. Brasília-DF, 2012. 68 p.

BRASIL. Ministério da Saúde. Secretaria de Atenção à Saúde. Departamento de Atenção Básica. Guia alimentar para a população brasileira. 2. ed. 1. reimpr. - Brasília: Ministério da Saúde, 2014. 156 p.

BRASIL. Ministério da Saúde. Portaria no 2.528 de 19 de outubro de 2006. Aprova a Política Nacional de Saúde da Pessoa Idosa. Diário Oficial da União, Brasília, DF, n. 202, 20 out. 2006.

CAMARGOS, M. C. S.; NASCIMENTO, G. W. C.; NASCIMENTO, D. I. C.; MACHADO, C. J. Aspectos relacionados à alimentação em Instituições de Longa Permanência para Idosos em Minas Gerais, v. 23, n. 1, p. 38-43, 2015.

CASAGRANDE, K. et al. Avaliação da efetividade da educação alimentar e nutricional em idosos. Revista Brasileira de Obesidade, Nutrição e Emagrecimento, v. 12, n. 73, p. 591-597, 2018.

CERVATO, A. M. et al. Educação nutricional para adultos e idosos: uma experiência positiva em universidade aberta para a terceira idade. Revista de Nutrição, Campinas, v.18, n.1, p. 41-52, 2005.

CHIARELLA, T. et al. A pedagogia de Paulo Freire e o processo ensino aprendizagem na educação médica. Revista Brasileira de Educação Médica, v. 39, n. 3, p. 418-425, 2015.

CHUNG, L. M. Y.; CHUNG, J. W. Y. Effectiveness of a food education program in improving appetite and nutritional status of elderly adults living at home. Asia Pacific Journal of Clinical Nutrition, v. 23, n. 2, p. 315-320, 2014.

CONSELHO FEDERAL DE NUTRICIONISTAS - CFN. Resolução CFN No 600 de 25 de Fevereiro de 2018. Dispõe sobre a definição das áreas de atuação do nutricionista e suas atribuições, indica parâmetros numéricos mínimos de referência, por área de atuação, para a efetividade dos serviços prestados à sociedade e dá outras providências, 2018. Disponível em https://www.cfn.org.br/wp-content/uploads/resolucoes/Res_600_2018.htm. Acesso em: 10 de abril de 2021.

DICIONÁRIO ONLINE DE PORTUGUÊS - DICIO. Significado de empoderamento Disponível https://www.dicio.com.br/empoderamento/\#: :text=substantivo $\% 20$ masculino $\% 20 \mathrm{~A} \% \mathrm{C} 3 \% \mathrm{~A} 7 \%$ C3\%A3o $\% 20 \mathrm{de} \% 20$ se, diz $\% 20$ respeito $\% 3 \mathrm{~A} \% 20$ empoderamento $\% 20$ das $\% 20$ mulheres Acesso em 10 de Abril de 2021.

FREIRE, P. A pedagogia da autonomia: saberes necessários à prática educativa. 43. ed. São Paulo: Editora. Paz e Terra, 2011. 
Ações de educação alimentar e nutricional na promoção de práticas alimentares saudáveis em idosas de uma instituição de longa permanência

GRILO, L. P.; CONCEIÇÃO, M. L.; DE MATOS, C. H.; DE LACERDA, L. L. V. Estado nutricional e práticas de educação nutricional em escolares. O Mundo da Saúde, v.40, n.2, p.230-238, 2016.

INÁCIO, M. L. C. Método intuitivo como metodologia inovadora para a prática em educação alimentar e nutricional. 2019. 85 p. Dissertação (Mestrado em Nutrição e Saúde) - Universidade Federal de Lavras, Lavras, 2019.

INCONTRI, D. Pestalozzi: Educação e ética. São Paulo. Scipione, 1997.

INSTITUTO BRASILEIRO DE GEOGRAFIA E ESTATÍSTICA - IBGE. Pesquisa Nacional por Amostra de Domicílios Contínua, 4a edição, Rio de Janeiro, 2019.

INSTITUTO BRASILEIRO DE GEOGRAFIA E ESTATÍSTICA - IBGE. Censo: expectativa de vida dos brasileiros, 2019. Disponível em: https://censo2021.ibge.gov.br/2012-agencia-denoticias/noticias/26103-expectativa-de-vida-dos-brasileiros-aumenta-para-76-3-anos-em-2018.html Acesso em 10 de Abril de 2021.

INSTITUTO DE PESQUISA ECONÔMICA E APLICADA - IPEA. Cuidados de longa duração para a população idosa: um novo risco social a ser assumido? Rio de Janeiro, 2010.

KAWAKAMI, R. M. S. A. et al. Perspectiva dos idosos sobre a experiência de morar só. Saúde Coletiva (Barueri), v. 10, n. 59, p. 4482-4487, 2020.

MELO, J. N. S.; MELLO, A. V.; COELHO, H. D. S. Consumo de alimentos ultraprocessados por idosos frequentadores de uma clínica integrada de saúde em São Paulo. Revista Saúde (Santa Maria), v. 46, n.1, p. 1-13, 2020.

MENDES, G. M.; OLIVEIRA, T. C. Assistência nutricional em instituição de longa permanência para idosos: relato de experiência. Revista Brasileira de Educação e Cultura, n. 18, p. 156-165, 2018.

MONTEIRO, C. A. et al. Increasing consumption of ultra-processed foods and likely impact on human health: evidence from Brazil. Public Health Nutrition, v. 14, n. 1, p. 5-13, 2011.

MURIMI, M. W. et al. Factors Influencing Efficacy of Nutrition Education Interventions: A Systematic Review. Journal of Nutrition Education and Behavior, v. 49, n. 2, p. 142-165, 2017.

OLIVEIRA, M. A. A escola elementar de Pestalozzi e Calkins: como ensinar número? Revista Linhas, v. 16, n. 31, p. 173-201, 2016.

PEREIRA, R. C.; INÁCIO, M. L. C.; PEREIRA, M. C. A. Educação alimentar e nutricional: das bases teóricas às experiências práticas. Lavras: Editora UFLA, 2019. 226 p.

PERONDI, C. Análise de práticas de educação alimentar e nutricional com grupos na atenção primária à saúde: uma abordagem freireana é possível? 2020, 121 p. Dissertação (Mestrado Profissional em Ensino e Saúde) - Universidade Federal do Rio Grande do Sul., 2020. 
Ações de educação alimentar e nutricional na promoção de práticas alimentares saudáveis em idosas de uma instituição de longa permanência

RAMOS, F.P.; SANTOS, L. A. S.; REIS, A. B. C. Educação alimentar e nutricional em escolares: uma revisão de literatura. Cadernos de Saúde Pública, v. 29, n. 11, p. 2147-2161, 2013.

ROCHA, G. O. et al. Avaliação nutricional seguida de ações educativas para promoção de hábitos alimentares saudáveis em mulheres com câncer de mama participantes de um grupo de apoio no sul de Minas Gerais. Interagir: Pensando a Extensão, v. 1, n. 21, p. 35-54, 2016.

WALLACE, R.; DEVINE, A. Tailored nutrition education in the elderly can lead to sustained dietary behavior change. The Journal of Nutrition, Health \& Aging, v. 20, n. 1, p. 8-15, 2016.

WORLD HEALTH ORGANIZATION - WHO. Diet, nutrition and the prevention of chronic diseases: Report of a Joint WHO/FAO Expert Consultation. Geneva: WHO Technical Report Series, v. $916,2003.168$ p.

WORLD HEALTH ORGANIZATION - WHO. Envelhecimento ativo: uma política de saúde. World Health Organization; tradução Suzana Gontijo. Brasília: Organização Pan-Americana da Saúde, 2005. 60 p.

Recebido em: 08/09/2020

Aceito em: 14/07/2021 